\title{
EDITORIAL
}

\section{Dementia-friendly communities: where home care and mental health intersect}

\author{
Erica Weir MD MSc, Dallas Seitz MD PhD
}

Cite as: CMAJ 2017 April 24;189:E581-2. doi: 10.1503/cmaj.170370

A s Canada's health minsters debate funding priorities for home care and mental health, we direct their attention to the report by the Standing Senate Committee on Social Affairs, Science and Technology ${ }^{1}$ that proposes a national strategy for dementia-friendly communities. These communities aim to build social networks and environments that support people living with dementia and their caregivers. ${ }^{2}$ Just as it takes a village to raise a child, it takes a community to care for an older adult with dementia.

The idea of developing dementia-friendly communities originated in Japan, travelled to Europe and recently landed in the Canadian Senate. In February 2016, the Senate committee was authorized to identify gaps in dementia care services in Canada and review approaches from other countries. It consulted caregivers and advocacy groups, as well as health care and residential service providers to generate recommendations spanning partnership, research, prevention and care.

The authors seem to have been inspired by Canada's accomplishments in cancer care. They recommended establishing the Canadian Partnership to Address Dementia with a mandate to create and implement a National Dementia Strategy. This partnership would have a structure and function similar to the Canadian Partnership Against Cancer, albeit with a more modest initial budget of $\$ 30$ million annually. They also recommended the allocation of $1 \%$ of current direct costs for dementia care, or about $\$ 100$ million annually, to the Dementia Research Strategy at the Canadian Institutes of Health Research. This compares reasonably to the $\$ 159$ million directed toward cancer research. ${ }^{3}$

Like cancer, dementia is a complex disease with a catch-all label to encompass different and sometimes concurrent pathologies. Unlike cancer, it almost never affects young people, and there are no effective drugs to cure or stop its progression. The current best treatment for dementia is not a pill, but another person, be it a family member, friend or health care provider. The current and proposed environment in which to deliver much of dementia treatment is not a tertiary health care facility, but an individual's community and home.

The toll on the caregiver at home intensifies as the disease progresses. People afflicted with dementia usually follow a slow tra- jectory of decline over many years that is marked by stages of cognitive deterioration and functional dependence on others. Most individuals can initially function at home with adequate supervision. Eventually, the individual needs around-the-clock cueing and assistance to manage even the most basic functions of dressing, toileting and mobilizing.

The responsibility on the informal caregiver - often an older spouse or working child - is heavy, demanding evermore vigilance and availability. Informal caregivers, $80 \%$ of whom are women, provide an average of 8.2 hours of support every day and night. ${ }^{1}$ Too often, this comes at the expense of the health of the spouse, or the income or job security of the child, and ends in caregiver isolation, depression and burnout. ${ }^{1,4}$

The committee attempts to address income loss with two recommendations for employment insurance and tax credits that were included in the federal budget of Mar. 22, 2017, ${ }^{5}$ but these are not sufficient. The community must step in to provide services and settings that share the caregiving load and thus protect the mental resilience and health of the informal caregiver. This includes having safe and supported assisted-living or long-term care places available before enough is too much for the caregiver.

Several of the committee's 29 recommendations focused on improving home care and residential systems, including targeting $\$ 3$ billion over four years for a comprehensive package of home care services. The committee gave special mention to models of home care delivery for rural and First Nations' communities, and recommended $\$ 540$ million to increase the capacity of long-term care facilities as much needed final destinations. This is a good starting point.

In the land of dementia-friendly communities, we imagine a place where home care and mental health intersect to care for those with the disease and the caregiver. We hope the ministers do as well.

\section{References}

1. Dementia in Canada: a national strategy for dementia-friendly communities. Ottawa: Standing Senate Committee on Social Affairs, Science and Technology; 2016. Available: www.alzheimer.ca/ /media/Files/national/Advocacy/ SOCl_6thReport_DementialnCanada-WEB_e.pdf (accessed 2017 Apr. 5). 
2. Wiersma EC, Denton Al. From social network to safety net: dementia-friendly communities in rural northern Ontario. Dementia 2016;15:51-68.

3. Cancer: about us. Ottawa: Public Health Agency of Canada; [modified 2016]. Available: www.phac-aspc.gc.ca/cd-mc/cancer/about-apropos-eng.php (accessed 2017 Apr.5).
4. 2017 Alzheimer's disease facts and figure. Alzheimer Dement. DOI: http:// dx.doi.org/10.1016/j.jalz.2017.02.001. In press.

5. Sibbald B, Eggertson L. Budget promises more mental health and veterans care. CMAJ 2017;189:E549-50.
Competing interests: Dallas Seitz received grant support from the Canadian Institutes of Health Research - Canadian Consortium on Neurodegeneration in Aging, and financial compensation from Cancer Care Ontario for his role as the Provincial Medical Lead for Dementia Capacity Planning in Ontario. No other competing interests were declared.
Affiliations: Associate Editor (Weir), CMAJ; Departments of Medicine and Public Health Sciences (Weir), Queen's University, Kingston, Ont.; Division of Geriatric Psychiatry and Department of Psychiatry (Seitz), Queen's University, Kingston, Ont.; Dementia Capacity Planning Project (Seitz), Cancer Care Ontario, Toronto, Ont.

Correspondence to: CMAJ editor, pubs@cmaj.ca 